\title{
原位电合成铜基金属有机框架介导合成的树枝状铜用于高效电催化还 原二氧化碳制备甲酸
}

\section{刘志敏}

中国科学院化学研究所, 北京分子科学国家研究中心, 中国科学院胶体、界面与化学热力学重点实验室, 北京 100190

\section{Highly Efficient Electroreduction of Carbon Dioxide to Formate over Copper Dendrites Derived from In Situ Electrosynthesized Copper- Metal-Oxide Frameworks}

\section{Zhimin Liu}

Beijing National Laboratory for Molecular Sciences, Key Laboratory of Colloid and Interface and Thermodynamics, Institute of Chemistry, Chinese Academy of Sciences, Beijing 100190, P. R. China

Email: liuzm@iccas.ac.cn.

Published online: June 2, 2020.
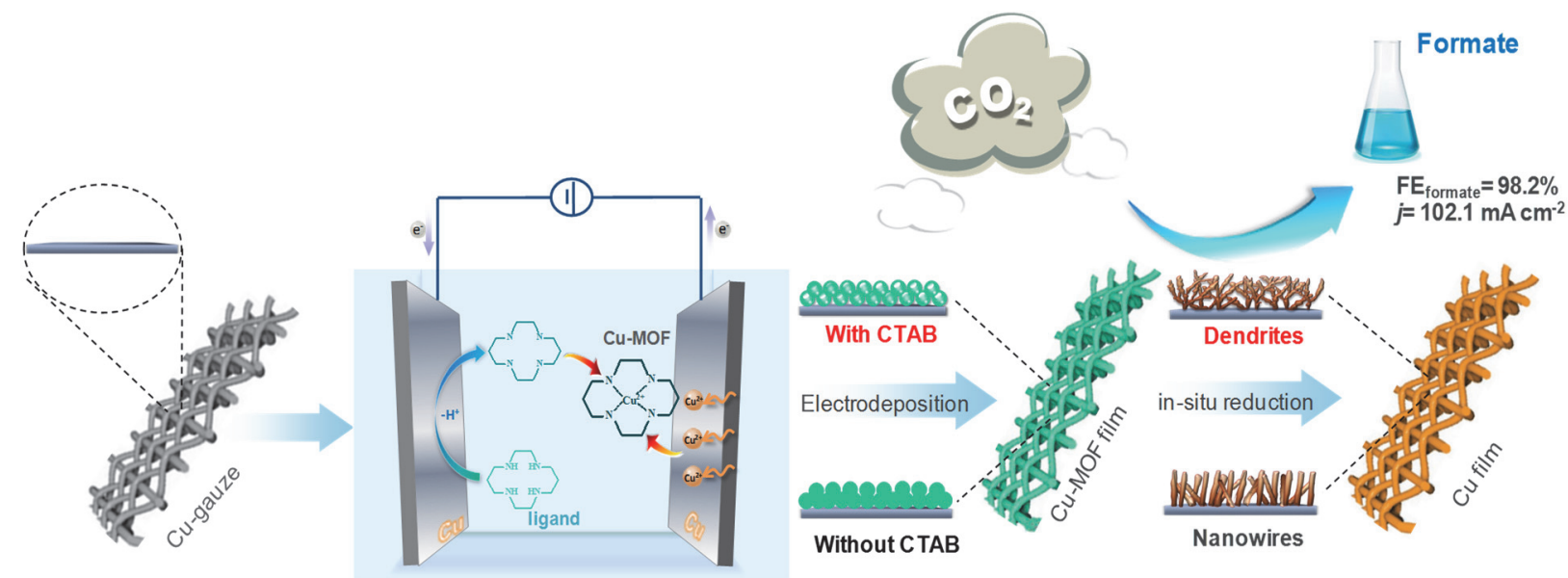

电催化剂制备及 $\mathrm{CO}_{2}$ 还原过程。

近年来, 电催化二氧化碳 $\left(\mathrm{CO}_{2}\right)$ 制备高附加价 值产物的研究备受关注, 但是如何实现在高电流 密度下高效还原 $\mathrm{CO}_{2}$ 为单一产物, 一直是该领域的 难点。在 $\mathrm{CO}_{2}$ 还原生成的各种产品中, 甲酸即可作 为液体燃料, 也是一种广泛的化工原料 1,2 。采用温 和、节能的电化学方法直接将 $\mathrm{CO}_{2}$ 还原为甲酸是重 要研究课题 3,4 。目前, 锡、铟和铅基材料对甲酸生 成有很好的催化活性, 但是这些材料通常需要较 高的过电位, 且催化效率较低。而电位或电流的 改变将显著影响其法拉第效率, 这导致甲酸生成 速率难以提高 5,6 。因此, 探索 $\mathrm{CO}_{2}$ 还原为甲酸的高
效电催化剂, 对 $\mathrm{CO}_{2}$ 转化和资源化利用具有重要 意义。

近日, 中国科学院化学研究所韩布兴研究员 课 题 组 在 Angewandte Chemie International Edition 上发表了题为 《Hollow Metal-OrganicFramework-Mediated In Situ Architecture of Copper Dendrites for Enhanced $\mathrm{CO}_{2}$ Electroreduction》的 文章 ${ }^{7}$ 。在催化剂合成中, 他们采用电化学辅助自 组装技术在3D铜纱基底上生长铜基金属有机框架 材料(Cu-MOF)薄膜。在此过程中, 采用表面活性剂 十六烷基三甲基溴化铵 (CTAB)作为调节 $\mathrm{Cu}-\mathrm{MOF}$ 
前驱体的结构导向剂。在 CTAB存在条件下, 疏水 面上的表面活性剂会减慢晶面的生长速度, 从而 形成空心 $\mathrm{Cu}-\mathrm{MOF}$ 材料。在 $\mathrm{CO}_{2}$ 电还原过程中, $\mathrm{Cu}-$ MOF很快原位还原为 $3 \mathrm{D}$ 树枝状铜电极。这一催化 剂对于 $\mathrm{CO}_{2}$ 还原为甲酸具有优异的催化性能。在离 子液体/乙腈/水的混合电解液中, 所制备的电极在 施加电压为 $-1.85 \mathrm{~V} v s \mathrm{Ag} / \mathrm{Ag}^{+}$时, 甲酸的法拉第效 率为 $98.2 \%$, 电流密度可达 $102.1 \mathrm{~mA} \mathrm{~cm}^{-2}$ 。

研究表明, 催化剂结构和电荷转移效应在 $\mathrm{CO}_{2}$ 还原中具有重要作用。1)空心Cu-MOF前驱体对于 构建具有树枝状结构的铜衍生物至关重要。原位 合成策略有利于暴露更多的活性位点并降低反应 的表面能, 从而降低起始电位并提高选择性; 2)树 枝状铜结构在3D铜纱基底上垂直生长, 形成大量 裸露的边缘, 提高催化活性; 3)电催化剂和铜基底 之间接触电阻小, 有利于提高电子传输速率, 降低 过电位和施加电压。以上三方面原因导致原位合 成的 $3 \mathrm{D}$ 树枝状铜催化剂对 $\mathrm{CO}_{2}$ 电化学还原具有优 异的催化性能。该工作为高效电还原 $\mathrm{CO}_{2}$ 为单一产 物提供了新思路。以上研究得到了国家自然科学 基金委、科技部国家重点研究计划的经费支持。

\section{References}

(1) He, M. Y.; Sun, Y. H.; Han, B. X. Angew. Chem. Int. Ed. 2013, 52, 9620. doi: 10.1002/anie.201209384

(2) Chen, Y.; Mu, T. C. Green Chem. 2019, 21, 2544. doi: $10.1039 / \mathrm{c} 9 \mathrm{gc} 00827 \mathrm{f}$

(3) Bai, X. F.; Chen, W.; Wang, B. Y.; Feng, G. H.; Wei, W.; Jiao, Z.; Sun, Y. H. Acta Phys. -Chim. Sin. 2017, 33, 2388. [白晓芳, 陈为, 王白银, 冯光辉, 魏伟, 焦正, 孙予罕. 物理化学学报, 2017, 33, 2388.] doi: 10.3866/PKU.WHXB201706131

(4) Lu, W. W.; Jia, B.; Cui, B. L.; Zhang, Y.; Yao, K. S.; Zhao, Y. L.; Wang, J. J. Angew. Chem. Int. Ed. 2017, 56, 11851. doi: $10.1002 /$ anie. 201703977

(5) Sun, Z. Y.; Ma, T.; Tao, H. C.; Fan, Q.; Han, B. X. Chem 2017, 3, 560. doi: 10.1016/j.chempr.2017.09.009

(6) Zhang, W. J.; Hu, Y.; Ma, L. B.; Zhu, G. Y.; Wang, Y. R.; Xue, X. L.; Chen, R. P.; Yang, S. Y.; Jin, Z. Adv. Sci. 2018, 5, 1700275. doi: 10.1002/advs.201700275

(7) Zhu, Q. G.; Yang, D. X.; Liu, H. Z.; Sun, X. F.; Chen, C. J.; Bi, J. H.; Liu, J. Y.; Wu, H. H.; Han, B. X. Angew. Chem. Int. Ed. 2020, 59, 8896. doi:10.1002/anie.202001216 